\title{
Leituras, diálogos e textos acerca de Paulo Prado: o Retrato do Brasil tematizado em periódicos ${ }^{1}$
}

Clayton José FERREIRA²

Resumo:

O ensaio Retrato do Brasil (1928) de Paulo Prado foi bastante tematizado em periódicos assim que foi publicado. A partir de cada leitura e narrativa criada pelos autores dos textos dessas mídias, são indicadas algumas possibilidades temáticas relevantes para aquela historicidade. A hipótese aqui é a de que tratar acerca do passado e de como representações históricas deveriam ser escritas é de grande importância para as reflexões a respeito das perspectivas de ação naquele presente para muitos daqueles intelectuais que escreviam nos diversos periódicos da época. Para este estudo, salientam-se as principais questões acerca do Retrato do Brasil que estão presentes nos textos de Oswald de Andrade, Mario de Andrade, João Ribeiro, Humberto de Campos e Jucá Filho em seus escritos para os respectivos periódicos: O Jornal; Diario Nacional: a democracia em marcha; Jornal do Brasil e Correio da Manhã.

Palavras-chave: Paulo Prado; periódicos; história da mídia; história das ideias.

\section{Readings, dialogues and texts about Paulo Prado: the essay Retrato do Brasil themed in Journals}

\begin{abstract}
:
Paulo Prado's essay Retrato do Brasil (1928) was extensively thematized in periodical's papers as soon as it was published. From each reading and narrative created by the authors of the texts of these media, some thematic possibilities relevant to that historicity are indicated. The hypothesis here is that dealing with the past and how historical representations should be written is of great importance for reflections on the prospects of action in that present for many of those intellectuals who wrote in the various newspapers of the time. For this study, the main questions about the Retrato do Brasil that are present in the texts of Oswald de Andrade, Mario de Andrade, João Ribeiro, Humberto de Campos and Jucá Filho in their writings for the respective journals are highlighted: O Jornal; Diario Nacional: a democracia em marcha; Jornal do Brasil e Correio da Manhã.
\end{abstract}

Keywords: Paulo Prado; periodical’s papers; media history; history of ideas.

\section{Lecturas, diálogos y textos sobre Paulo Prado: o Retrato do Brasil temático en publicaciones periódicas}

\section{Resumen:}

El ensayo Retrato do Brasil (1928) de Paulo Prado fue fuertemente tematizado en revistas tan pronto como fue publicado. A partir de cada lectura y narrativa elaborada por los autores de los textos de estos medios se señalan

\footnotetext{
${ }^{1}$ Este texto é resultado parcial de minha tese e de meus primeiros estudos durante o estágio de pós-doutorado. Agradeço ao supervisor Prof. Dr. Marcelo de Mello Rangel e a revisão da professora Ma. Helena Azevedo Paulo de Almeida.

2 Pós-doutorando em História pela Universidade Federal de Ouro Preto (UFOP). Doutor em História pela Universidade Federal de Ouro Preto (UFOP).E-mail: claytonjf15@hotmail.com.
} 
algunas posibilidades temáticas relevantes para esa historicidad. La hipótesis aquí es que tratar el pasado y cómo deben escribirse las representaciones históricas es de gran importancia para las reflexiones sobre las perspectivas de acción en ese presente para muchos de los intelectuales que escribieron en las distintas revistas de la época. Para este estudio, se destacam las principales cuestiones sobre el Retrato de Brasil que están presentes en los textos de Oswald de Andrade, Mario de Andrade, João Ribeiro, Humberto de Campos y Jucá Filho en sus escritos para las respectivas revistas: O Jornal; Diario Nacional: a democracia em marcha; Jornal do Brasil y Correio da Manhã.

Palabras clave: Paulo Prado; publicaciones periódicas; historia de los medios; historia de las ideas.

\section{História e narrativas}

Podemos refletir a respeito das possibilidades da historicidade próprias à escritura e leitura do ensaio O Retrato do Brasil: ensaio sobre a tristeza brasileira (1928), de Paulo Prado (1869-1943), a partir dos periódicos (jornais, revistas, almanaques, etc.) que abordaram muitas das suas questões. ${ }^{3}$ Neste sentido, ensaios e periódicos compõe determinadas constituições do passado e são ambos importantes aspectos para a compreensão de parte de determinada historicidade.

Não pretendo realizar uma história da recepção do livro Retrato do Brasil. Partindo de um esforço mais modesto, o que tento neste texto é discorrer a respeito de como alguns integrantes das comunidades letradas brasileiras no início do século XX debateram, no interior de seus limites históricos, alguns tópicos, questões, argumentos e enunciados tratados no ensaio de Prado. E ainda, como produziram suas próprias leituras, representações e conteúdos sobre os processos históricos que foram e estavam sendo vivenciados e tematizados. Se compreendermos os ensaístas como intelectuais, pressupondo intelectual como “[...] uma categoria sócio-profissional de contornos pouco rígidos, ou seja, como produtores e mediadores de interpretação da realidade social que possuem grande valor político" (GOMES, 2009, p. 26), também entendemos deste modo aqueles que escreveram para tais periódicos, exercendo simultaneamente as mais diversas atividades (polígrafos). Enquadram-se na mesma categoria

\footnotetext{
${ }^{3}$ Com formação de bacharel em Direito em 1899, Prado teve participação fundamental com sua esposa, Marinette

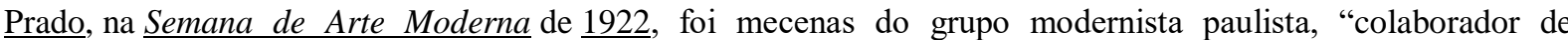
importantes periódicos paulistas, como O Estado de S. Paulo, Correio da Manhã, Jornal do Comércio e Revista do Brasil, além de ter participação ativa na fundação de importantes revistas modernistas (Klaxon, Terra Roxa e outras terras e Revista Nova) e no próprio movimento da Semana de Arte Moderna. Após o encerramento da Revista Klaxon, em 1923, Paulo Prado assume a Revista do Brasil, que de 1918 a 1925 foi controlada por Monteiro Lobato. A principal mudança dessa nova direção será a utilização da Revista como veículo de divulgação do movimento modernista, em oposição ao caráter acadêmico que antes a definia" (AGUIAR, 2014, p. 20-21).
} 
aqueles que produziam trabalhos em outros gêneros, mídias, outras áreas de conhecimento e saberes diversos, das artes, militâncias, etc. ${ }^{4}$

O espaço público, portanto, é entendido também como aquele onde se realiza a política, a partir, dentre outras possibilidades, da imprensa e dos impressos. ${ }^{5}$ Como aponta Palti, a respeito do novo léxico político que surge na América Latina, por meio da intensificação e ampliação da imprensa no início do século XX:

O jornalismo aparecerá, ao mesmo tempo, como uma maneira de discutir e fazer política. E isso também infunde uma nova consciência sobre a performatividade da palavra no sentido de sua "criatividade": a imprensa periódica não só buscava "representar" a opinião pública, mas tinha a missão de constituí-la como tal (PALTI, 2007, p. 197, tradução nossa).

Como parte desse momento histórico, muitos intelectuais se preocuparam, assim como Prado, em refletir mediante perspectivas ético-políticas. Deste modo, o campo intelectual se encontra conectado à ação política. ${ }^{6}$ Dito de outro modo,

[...] uma das premissas da reflexão é que, no Brasil de fim do século XIX e das primeiras décadas do XX, não é consistente (empírica e teoricamente) assumir uma separação entre campo intelectual e político, embora seja possível reconhecer uma relativa e crescente autonomia na dinâmica de cada um deles (GOMES, 2009, p. 26).

\footnotetext{
${ }^{4}$ Com exceção de Cecília de Lara, no ano de 1977, os autores dos textos que trataram o ensaio em questão são homens. Mesmo a entrevista com a poetisa Gilka Machado é assinada por Godin da Fonseca. Dito isto, é preciso frisar a existência de um grande número dessas intelectuais, que, resistindo às constituições machistas violentas de sua historicidade, escreveram ricos e diversos trabalhos. As referências dos textos de muitas dessas autoras podem ser encontradas nos três volumes do livro Escritoras brasileiras do séc. XIX, organizados por Zahidé Lupinacci Muzart, e no livro Ensaístas brasileiras: mulheres que escreveram sobre literatura e artes de 1860 a 1991.

${ }^{5}$ Segundo Habermas, o surgimento das ideias de "causas públicas" e "interesse público" apenas tornou-se parte de uma linguagem política quando diversos processos históricos constituíram o confronto entre "Estado" e "Sociedade" na modernidade ocidental. "Esse pano de fundo histórico forma também o contexto para o interesse específico em uma esfera pública que somente é capaz de assumir funções políticas na medida em que possibilita aos cidadãos da economia, na qualidade de cidadãos do Estado, estabelecer compromissos ou universalizar seus interesses e torna-los tão efetivos a ponto de o poder do Estado se transformar no medium fluido de uma autoorganização da sociedade" (HABERMAS, 1984, p. 51).

${ }^{6}$ Apesar da grande importância de tratarmos das filiações políticas e principais perspectivas dos editoriais desses periódicos e dos seus autores, nosso foco aqui serão os textos, as concepções semânticas acerca de determinados passados e especialmente de sua contemporaneidade a partir de explanações a respeito do ensaio de Prado.
} 


\section{Múltiplos olhares de um retrato}

Oswald de Andrade (1890-1954) salienta que a documentação recolhida por Prado o auxilia na constituição de argumentos, no entanto, a análise do Brasil a partir de certas compreensões morais nos dois primeiros capítulos seria um erro: "nota-se que o 'Retrato do Brasil' nesse capítulo é a repetição de todas as monstruosidades de julgamento do mundo ocidental sobre a América descoberta" (ANDRADE, O., 1929, p. 2). Prado se basearia em certo pensamento missionário, numa moralidade cristã, a qual julgaria outros fenômenos históricos e culturais de forma autocentrada, juízo que, segundo Oswald, teria perdido sua validez na contemporaneidade. Tais perspectivas seriam aquelas que teriam orientado a crítica intensa à "luxúria" no livro em questão. Nomeando o ensaio como "pré-freudiano", Oswald critica o argumento de que a liberdade sexual intensa acarreta determinadas patologias sociais. Menciona, inclusive, que a perspectiva da autonomia moral e do intelecto seriam marcas da própria trajetória pessoal de Prado:

Atribuo à preguiça aristocrática do autor de "Paulística" as conclusões opostas à alta liberdade moral e intelectual professada a vida toda por ele. Há mesmo violentos choques entre a verdade documentada e o julgo emitido. [...] Estou convencido de que a orientação de "Retrato do Brasil" é em parte uma homenagem ao nosso "meio culto" representado com certeza por Capistrano de Abreu. Creio mesmo, que o respeito ao grande historiador patrício foi que prendeu Paulo Prado de um modo tão violentamente sentimental à tese francamente missionária e catequista em que ele se aventura (ANDRADE, O., 1929, p. 2).

Sobre uma estética no ensaio, Oswald salienta a presença de um esforço descritivo o qual possui grande vitalidade ao tornar presente a natureza, os ambientes, os quadros históricos e os corpos humanos aos quais se refere. E isto também por meio de um suporte documental, ou, ainda, no interior também de sua preocupação com o que seria uma representação histórica próxima aos métodos da disciplina:

O "Retrato do Brasil" tem passagens lindas. As descrições das matas do Norte nos transportam para elas e para os momentos integrais da nossa natureza bruta e sensual. Os quadros da vida de luxo de senhores, escravos negros e índios, os séquitos, as procissões, os corpos nus sob a cambraia caseira, tudo isso bem documentado, bem pintado, bem vivido, é um hino que fura qualquer 
invólucro de falso pessimismo e a gente sente em cada página assim colorida o arrimo histórico de "Macunaíma" (ANDRADE, O., 1929, p. 2).

Em O turista aprendiz, Mario de Andrade (1893-1945) escreve por meio de descrições, metáforas, analogias e epifanias, produzindo um texto mais propriamente inclinado a isso que seria uma perspectiva estética da narrativa (se dirigindo aos sentidos e à afetividade do leitor). Inicia dizendo que "[...] deixei de ser um indivíduo compreensivo para me tornar essencialmente, unicamente mesmo, sensitivo" (ANDRADE, M. 1929, p. 8). O poeta parece querer insinuar que Prado, mesmo sendo um homem mais prático, teria feito algo de similar.

Esta história de raciocinar durante a sensação dá no caso daquele que não quero nomear mas, tomando outro dia Whisky, com agua de coco, bebidinha santa! - me falou:

- Paulo Prado não tem razão não! Então o Brasil não há de ser grande como uma bebida dessas!...

É uma burrada esplêndida. Tenho, aliás, achado muita graça na reação patrioteira que o livro de Paulo Prado causou. O "Retrato do Brasil" está sendo lido e relido por todos. E comentado. Comentado pra atacar. Inda não topei com ninguém que concordasse com o livro. Isso me diverte porque toda a gente ataca a letra deste trabalho tão subtil e acaba concordando, com o espírito dele. Acham que o livro é ruim, o Brasil não é só aquilo, a sensualidade não entristece ninguém, o brasileiro não é triste, mas com palavras diferentes o que todos acham mesmo é que "o Brasil vai mal" (ANDRADE, M., 1929, p. 8).

O autor de Macunaíma aponta que as compreensões históricas de Prado e suas conclusões soturnas são provocações, as quais querem chamar a atenção para problemas e limites próprios ao seu tempo, especialmente ao Brasil. Mario de Andrade sublinha que as críticas e posições de Prado, mesmo que próximas de um pessimismo pretendem provocar à ação.

Paulo Prado é uma inteligência fazendeira prática. Fazendeiro sai na porta da casa, olha o céu, pensa: vai chover. Chama o administrador e fala:

- Vai chover. Ponha os oleados no café.

Pouco importa que o céu esteja puro, fazendeiro sentiu que ia chover. Pouco importa que chova ou não (e no geral chove mesmo), o importante é que se chover o café esteja coberto. Foi o que Paulo Prado fez. A moral do "Retrato do Brasil" é bem unicamente essa:

-"Vai chover" (ANDRADE, M., 1929, p. 8). 
Ainda que esteja equivocado em alguns momentos ou em parte das suas conclusões, tão polêmicas acerca de uma "tristeza" generalizada, ou da própria proximidade da "guerra" e da "revolução", o Retrato do Brasil seria como um alerta para incomodar, tentando evitar tais consequências. Para Mario de Andrade, pouco importa se suas conclusões eram acertadas, o importante era produzir uma pragmática que alertasse, tentando sentir o clima daquele presente por intermédio do passado. Com isso, estaria se atentando para a necessidade da ação no que diz respeito a certos problemas historicamente constituídos. No interior disso, preocupado em fundamentar e produzir interpretações a respeito do passado, também se torna central realizar uma reflexão sobre o presente, mediante a tematização da história. Mesmo que não "chova", Mario de Andrade reitera que Prado teria se preocupado em tentar "sentir, afirmar e prevenir" quando compreendeu que as experiências do passado talvez indicassem um horizonte acinzentado: "O importante era sentir, afirmar e prevenir: 'vai chover'” (ANDRADE, M., 1929, p. 8).

João Ribeiro (1860-1934), autor de História do Brasil, aponta que o ensaio de Prado contribui para o entendimento de alguns aspectos da história brasileira e o peso dessas experiências para o presente. No entanto, acrescenta que o livro é naturalmente parcial e limitado e possui certa pretensão heurística equivocada em sua conclusão acerca da "tristeza", provocada pela "cobiça" e "luxúria":

As vezes é o título de um livro que predispõe a crítica a restrições excessivas. $\mathrm{O}$ - Retrato do Brasil - tem o defeito de não ser um retrato; é apenas um dos aspectos verdadeiros mas incompletos por só contemplar, por assim dizer, uma das dimensões do grande corpo. Pinta-nos o artista um pouco tendenciosamente a nossa tristeza que me parece problemática. A terra dos feriados, do amanhã - do tenha paciência - da oratória - do carnaval - não pode ser o habitat da melancolia. É talvez a terra da preguiça, da irresolução, da palavra sem facto, da vida contemplativa (RIBEIRO, 1928, p. 6).

Os motivos para que se culminasse na tristeza seriam "vagos ou contraproducentes", já que a "luxuria" e a "cobiça" são, para Ribeiro, antes causas para "a vida alegre e as longas esperanças de riqueza e de otimismo" (RIBEIRO, 1928, p. 6). A argumentação de Prado seria "bem arquitetada", mas suas conclusões acerca da tristeza estariam equivocadas e fantasiosas, ou, ainda, “a sua indução é razoável, mas a sua dedução é fantástica” (RIBEIRO, 1928, p. 6). 
O ensaio em questão é entendido por Ribeiro como insuficiente em suas compreensões e generalizações acerca do peso e da pressão realizada pelas experiências históricas no presente.

Mas, apesar de sua ironia, parece entender que o livro possui boas reflexões e aspectos representativos de determinadas experiências passadas: “[...] é uma pintura magnífica em que não reconhecemos o original, mas admiramos os efeitos de luz e a modelação e distribuição das massas, retrato de avô longínquo que faria excelente figura numa galeria de antepassados" (RIBEIRO, 1928, p. 6).

Pessoalidades e generalizações são indissociáveis ao historiador e não seriam, necessariamente, problemas no interior da escrita histórica. O problema estaria no excesso, na falta do que podemos chamar rapidamente de uma preocupação mais metódica. São exacerbações que produzem compreensões duvidosas, percepção que Ribeiro constrói por meio da crítica de Taine a respeito de Michelet. Apesar disto, as representações realizadas por Prado são caracterizadas como uma "narrativa empolgante", que "evocam" e "ressurgem" aspectos dessas experiências (RIBEIRO, 1928, p. 6). Assim, Ribeiro (1928, p. 6) salienta algumas imagens apresentadas por Prado a partir da representação do passado, por meio de recursos sensoriais e afetivos: "realmente, há muitas das feições primitivas do Brasil, a saudade dos fugitivos, dos expatriados, a dor das distâncias da pátria, desmaiadas em um cenário novo e mais propício". As capacidades imaginativa e interpretativa, associadas à afetividade, são concebidas pelo historiador sergipano como aspectos importantes, mas podem comprometer parte das conclusões do historiador, caso não sejam mediadas.

Os documentos para os pequenos historiadores sem ideias são um manancial de verdades, mas para um homem de imaginação e espírito como Paulo Prado, constituem matéria para sínteses e generalizações muito contestáveis. Evocam, ressurgem, mas pode-se dizer como de Michelet dizia de Taine: se doute. Sucedeu a Paulo Prado o mesmo que sucederia a Capistrano se tentasse uma síntese. Ninguém como ele teria o amplo domínio do material escrito, mas nem por isto poderia libertar-se de seus apriorismos, ou seja, preconceitos de generalização (RIBEIRO, 1928, p. 6, grifo do autor).

Ao salientar a proximidade entre Prado e Capistrano de Abreu, percebe-se que, para Ribeiro, a pesquisa e a escrita da história não se limitam à análise da documentação como se ela pudesse oferecer o conhecimento verdadeiro e inquestionável do passado. Pesquisa e escrita estariam sujeitas não somente às determinações do presente e da individualidade do historiador, 
mas aos documentos escolhidos (arbitrariamente ou não) e/ou disponíveis. No entanto, era preciso atenção no exagero hermenêutico e nas perspectivas generalistas.

O jornalista Humberto de Campos (1886-1934) inicia a sua crônica sobre o ensaio Retrato do Brasil, no jornal Correio da Manhã, com a compreensão de que o comportamento libidinoso teria composto a mentalidade de um novo tipo étnico no Brasil, "apresentando como expoente desse sentimento o Barão, no Império e, na República, os coronéis sertanejos, arrastados muitas vezes até o crime pela mais desregrada concupiscência” (CAMPOS, 1928, p. 2). Campos (1928) aponta o quanto a temática, a da luxúria no contato entre portugueses e indígenas, teriam sido centrais em diversos livros, mencionando Caramuru, de Santa Rita Durão; O Uruguai, de José Basílio da Gama; Vila Velha, de Claudio Manoel da Costa; e os poemas Potira e Cristã Nova, de Machado de Assis. Parece, assim, insinuar a importância da questão como definidora de certo caráter nacional.

Já a cobiça, antes mesmo da luxúria, teria lançado ao mar os povos europeus. Para o cronista, contudo, Prado teria errado ao interpretar que o brasileiro é um povo caracterizado pela tristeza, especialmente na ideia de que a luxúria e a cobiça exacerbada resultam em tristeza generalizada. Para ele, apesar de que a geografia é a responsável pela possibilidade ou não de efetivação do que considera avanço civilizacional, os próprios elementos étnicos dos portugueses e dos indígenas, definidos por sua alegria, teriam dado origem a outro tipo étnico que possuía esse mesmo traço de felicidade. ${ }^{7}$

As duas parcelas gerais alinhadas pelo historiador e sociólogo paulista [cobiça e luxúria] acham-se rigorosamente certas. Mas o sr. Paulo Prado enganou-se na operação. A sua formula é esta: Luxúria + Cobiça $=$ Tristeza. Mas onde se confirma esta soma? O brasileiro não é, absolutamente, um povo triste, nem tem de onde lhe venha esse mal. O português é jovial, festeiro, comunicativo. O saudosismo de que falam seus historiadores é mais literário do que popular. [...] E o nosso índio não o era menos. As suas festas eram barulhentas, tumultuosas e duravam dias, ás vezes semanas. Os cronistas dos séculos XVI e XVII são unanimes em proclamar a sua brejeirice, o seu amor à galhofa, às pilherias, ao riso franco, às grandes folganças ruidosas, quando reunidos, como se pode ver, para citar um exemplo, em Leri, naquela visita à aldeia de Euramiri, em que os antropófagos passaram a noite em gritaria e trejeitos, com

\footnotetext{
${ }^{7}$ Há, de forma sutil no texto de Campos, o equivocado topos de uma certa "democracia racial" fundada a partir de europeus e etnias indígenas e africanas. Nota-se também que os indígenas que menciona sempre são os de um passado remoto, como se não houvessem etnias em sua contemporaneidade, o que é bastante comum entre os letrados do período.
} 
o exclusivo propósito de alegrar o estrangeiro. $\mathrm{O}$ nosso indígena, isoladamente, era, de fato, taciturno. Mas, ser taciturno não é ser triste. [...] $\mathrm{O}$ brasileiro, como acima se disse, pode ser taciturno, mas não é triste. Predominam na sua formação moral as qualidades fundamentais do seu antepassado americano, cuja contribuição, para a constituição da sua psique, foi muito maior do que se tem proclamado. A sub-raça brasileira, já definida desde o século XVIII, deve ter, pelo menos, $50 \%$ de sangue indígena (CAMPOS, 1928, p. 2).

Partindo dessa crítica às conclusões de Prado, Campos (1928) realiza certo exercício antropológico interessante, assinalando que cada conceito de alegria é produzido historicamente e culturalmente em cada espaço, constantemente parecendo estranho para o olhar do outro. Prado teria se equivocado em sua conclusão a respeito de uma tristeza brasileira, devido a sua erudição (como de tantos outros intelectuais) estar fundada em estudos e conceitos de referencial europeu. Desse modo, o autor não conseguiria reconhecer outra experiência semântica de tristeza ou alegria vinculada a outro povo, mesmo em sua própria nacionalidade, já que toma uma determinada especificidade conceitual, uma forma, como uma generalidade, quase como uma filosofia antropológica. Ou seja, Prado entenderia o conceito de tristeza elaborado pela intelectualidade europeia como algo comum a toda cultura no tempo e espaço. Para o cronista, esse seria um traço comum dos homens de letras brasileiros em sua formação, sendo que estariam equivocadamente sempre focados em outras culturas como padrão desse ideal civilizacional e de progresso linear, o qual acreditam que outros países e povos deveriam emular.

A interpretação dos dois traços capitais do semblante do Brasil, que nos é dado pelo sr. Paulo Prado tem, entretanto, uma explicação. É que o autor possui um padrão para a alegria, talvez o padrão francês, talvez o americano do norte. Mas a alegria é como a felicidade: assim como todo o indivíduo tem seu modo de ser feliz, cada povo tem a sua maneira de usar da alegria. Diante de um francês, principalmente de um parisiense, um inglês dará a impressão de uma criatura com ideias de suicídio. E no entanto, os anglo saxônicos são um povo alegre; alegre a sua maneira, mas alegre. [...] Será por tristeza, então, que centenas de milhares de pessoas se deslocam dos seus bairros, nas capitais brasileiras, para gritar, berrar, cantar, pular e serem pisadas, e empurradas, nos dias de carnaval? Serão expressão de tristeza as bandas de música que sonorizam as mais remotas aldeias sertanejas, e as festas de arraial que são por toda a parte o complemento profano de todas as solenidades católicas? Absolutamente, não. Nós, homens de letras brasileiros, é que, formando a nossa cultura à europeia, deixando-nos absorver pelo espirito europeu, 
julgamos que o nosso povo está fora do nosso caminho quando nós é que nos desviamos do nosso e nos tornamos estrangeiros ao lado dos nossos irmãos (CAMPOS, 1928, p. 2).

Nessa passagem, Humberto de Campos aponta que o mesmo padrão europeu, no qual se formam os letrados brasileiros, está associado à noção de modelo civilizacional. A partir das comparações, cria-se uma expectativa e uma sensação de atraso frente ao padrão europeu, mesmo no interior de uma experiência em constantes transformações e instabilidades cotidianas (acelerada). Seriam os próprios intelectuais, como Prado, que estariam se afastando da compreensão da experiência civilizacional singular que estaria em processo de elaboração no Brasil. Campos acrescenta que, sendo aparentemente a experiência estadunidense um modelo civilizacional para Prado, mesmo assim o autor do retrato não teria se atentado a especificidade histórica da formação dos Estados Unidos.

Para o cronista, interessaria menos a composição étnica na formatação de um povo, o que, de fato, seria importante é a capacidade de adaptação de um grupo étnico e cultural a um novo espaço, a novas propriedades geográficas. O norte das Américas estaria, assim, espacialmente adequado em suas características topográficas para os europeus que ali se instalaram. ${ }^{8}$ A adaptação de europeus em espaços diferentes do seu clima, associados aos elementos étnicos e culturais dos outros grupos que se encontravam aqui e daqueles escravizados na África, comporiam um novo tipo humano, físico e mental, o qual, para Campos, está em processo de formação de um novo perfil civilizacional.

O padrão da civilização perfeita, segundo se conclui do paralelo que estabelece na terceira parte da obra, é norte-americano. E este confronto é estranhável em um estudioso de leituras tão complexas como o sr. Paulo Prado. Esquece o ilustre escritor que o caso dos Estado Unidos é único na história da civilização, na idade moderna. Os americanos não devem a harmonia da sua formação a nenhum fator histórico, ou étnico, mas, preliminarmente, ao fator geográfico. O povoamento do Mundo Novo só podia ser feito pelo europeu. Para estabelecer-se nos Estados Unidos, este não se deslocou do seu clima, da zona a que a raça branca se adaptou desde a definição do seu tipo. [...] Para fixar-se na América do Sul, e especialmente no Brasil, entre $5^{\circ} \mathrm{I} 0^{`}$ lat. Norte e $33^{\circ} 46$, I0` lat. Sul, ele sofre um deslocamento de tal maneira profundo que tem que modificar o seu tipo e o seu gênio, para poder adaptar-se. É essa adaptação que estamos sofrendo. Com ou sem os

\footnotetext{
${ }^{8}$ Campos não menciona que a maior parte da população envolvida no processo no interior do território onde hoje são os Estados Unidos eram nativos americanos, população africana escravizada, entre outros.
} 
fatores étnicos, nos [sic] temos que possuir a nossa raça, e como toda a família humana que se caracteriza, a nossa forma de civilização. Dos confrontos indevidos é que saem as conclusões erradas (CAMPOS, 1928, p. 2).

$\mathrm{Na}$ construção de seu argumento, menciona que existem diversas formatações civilizacionais, possibilidades outras, diferentes do arquétipo europeu. Seria preciso reconhecer tal perspectiva para compreender que outros percursos históricos encaminhariam em outras formas de organização e desenvolvimento dos povos. Uma perspectiva muito interessante, que apresenta um entendimento complexo da história como processos diversos em espaços e culturas diferentes, não como percurso linear que generaliza todos os grupos humanos em uma direção. Novamente há uma interessante crítica direcionada ao padrão de civilização (e do conceito de felicidade) europeu e/ou estadunidense de Prado, o qual o teria impossibilitado de reconhecer como civilização a própria sociedade que faz parte. $\mathrm{O}$ exemplo japonês é apresentado como dessemelhante do europeu, o qual, no entanto, não pode deixar de ser reconhecido como uma civilização.

\begin{abstract}
Nós temos realizado, como povo, com os elementos negativos que o Destino nos deu ao fazer a distribuição do planeta, um dos maiores milagres da civilização contemporânea. $\mathrm{O}$ sr. Paulo Prado não o reconhece por ter estabelecido, com a sua cultura multiforme, o "standard" da felicidade humana. A civilização japonesa parecer-se-á, acaso, com a europeia ou a americana? E não será, no entanto, uma civilização? Pois, assim nos sucederá a nós: nós teremos um tipo brasileiro, uma civilização brasileira, e, com esse tipo, uma alegria brasileira. O tipo e a alegria já existem: o homem é raquítico, pequeno, mas resistente; e a alegria nada se parece com a de qualquer outro povo, mas é alegria. Quanto a civilização, ela será a soma de todos os nossos defeitos, de nossos vícios, das nossas qualidades, dos nossos sentimentos, daquilo que nós carecermos e tivermos conseguido, independente das necessidades e dos exemplos alheios (CAMPOS, 1928, p. 2).
\end{abstract}

$\mathrm{Na}$ continuidade de sua reflexão, diferente das compreensões até então apresentadas, Campos caminha para uma ideia problemática, adentrando a uma perspectiva centrada nos padrões europeus que criticou em Retrato do Brasil. Para ele, existe um processo de adaptação das populações resultantes da miscigenação na geografia das regiões tropicais, uma região que, segundo Campos, não seria propensa à civilização. ${ }^{9}$ Nessa passagem, a partir de seu próprio

\footnotetext{
${ }^{9}$ Campos escreve a partir de uma imagem da mulher indígena historicamente equivocada, e isto a partir de um imaginário que atribui às etnias indígenas uma desacertada característica selvagem e incivilizada frente a um
} 
padrão civilizacional europeu, escreve que não há civilizações nas regiões dos trópicos - uma ideia de oposição entre natureza e civilização muito semelhante à de Buckle. Mesmo reconhecendo e refletindo a partir da possibilidade de uma civilização diferente do modelo europeu, como a japonesa, suas compreensões se encontram bastante análogas ao ideal europeu o qual, em geral, exclui outras organizações étnicas como civilização: "O Brasil está, quase todo, dentro do anel geográfico que compreende, em torno do planeta, o Congo, a África Portuguesa, Madagascar, a Zimbésia, e, na Oceania, a Polinésia, Sumatra, Java, Bornéo, a Nova Guiné e o Norte da Austrália", e conclui: "E que civilizações existem nessa latitude?" (CAMPOS, 1928, p. 2).

A inserção do presente do sujeito que pensa sobre o passado como um equívoco é tema primordial do próximo texto abordado. Em artigo intitulado "Anacronismos", escrito para o Correio da Manhã, em 1929, Candido Jucá Filho escreve: “Uma das tarefas mais penosas a que nos podemos oferecer é a de imaginar o Passado desvestindo-o completamente de quantos 'presentismos' nos dominam o espírito" (JUCÁ FILHO, 1929, p. 1). Dando ao passado característica imperativa, entende que aquele que investiga algo sobre o passado sofre grande dificuldade em realizá-lo sem estar trajado com suas perspectivas contemporâneas, as características históricas daquele que pensa sobre o passado.

Ocorre-me essa reflexão a propósito desta bela e nascente literatura no Brasil, que visa engrandecer a nossa história anedótica. Alguns escritores, dotados de intuição maravilhosa, tem de fato conseguido interpretações exatas de fatos e costumes passados. Outros, porém, desajudados de talento crítico, falham redondamente na sua intenção, e do nosso pretérito não apresentam senão belas fantasias literárias, que examinadas com atenção enxameiam de anacronismos (JUCÁ FILHO, 1929, p. 1).

De forma semanticamente diferente da que compreende Hartog (2014) ao utilizar do neologismo presentismo, Candido Jucá entende a categoria como as características inerentes de um presente, de um momento histórico (historicidade), na mentalidade do sujeito. No entanto,

eurocentrismo: "A índia tornou-se, então, o centro de todos os choques. Combatia-se em torno da fêmea bruta, sem higiene e sem beleza, como se combatera, dois séculos antes, sob as ameias dos castelos medievais, pelo vago perfume de uma flor de crepúsculo" (CAMPOS, 1928, p. 2). Outra passagem acentua esse imaginário equivocado: "[Prado] acentuou aquele lineamento, aprofundou-o, desenvolveu-o, associando ao reinol, como fator deste pecado que nos dá uma das originalidades do caráter, o próprio indígena, cuja vida lasciva, corrupta, depravada, obscena, foi um dos motivos de escândalo dos primeiros catequistas" (CAMPOS, 1928, p. 2). 
o linguista acredita ser possível produzir "interpretações exatas de fatos e costumes passados" através de uma hermenêutica a qual parte de certa reflexão lógica e formal, ou "talento crítico", somado a uma percepção sensível, ou "intuição maravilhosa” (JUCÁ FILHO, 1929, p. 1). ${ }^{10}$ No entanto, este não seria exatamente o caso de Prado.

Apesar de não eliminar completamente a credibilidade do ensaio como representação de certas experiências passadas, para Jucá Filho, os anacronismos de Prado sujeitariam o seu livro a certa invalidade. Assim como apontou Oswald de Andrade, o linguista escreve que no interior do Retrato do Brasil há um julgamento da moralidade colonial a partir de aspectos comuns à historicidade do início do século XX, e não aqueles próprios ao recorte analisado. Tal anacronismo seria ainda mais problemático pelo fato de que Prado tenta comprovar seus julgamentos por meio de um uso equivocado de algumas fontes, os relatos de viajantes, como se estivessem em acordo com os julgamentos do paulista, como se evidenciassem tais interpretações.

\begin{abstract}
Não basta aprofundado conhecimento da história episódica para bem julgar os homens de outros tempos. A crítica psicológica é de importância capital. Em cada era, a civilização e a cultura criam sentimentos e paixões que nos cumpre conhecer, se não queremos julgar injustamente que mais que as considerações econômicas, definem as épocas, e são a alma dos acontecimentos. Para descrever uma revolução ou um homem, importa penetrar-lhes as condições psicológicas. Se não é razoável estudar a história do Egito, segundo o materialismo histórico, ou pretender descobrir patriotismo em Julio Cesar, também é insensato fazer um gentio amar com todas as veras do romantismo, ou de qualquer maneira querer situar em dias de antanho os fenômenos que vinculam a sociedade de hoje (JUCÁ FILHO, 1929, p. 1).
\end{abstract}

Jucá Filho se atenta para um problema antropológico. O estranhamento do comportamento moral não ocorre somente a partir da diferença entre as experiências temporais, mas também entre as diferenças espaciais. Ou melhor, cada agrupamento humano, no interior

\footnotetext{
${ }^{10}$ Seria um anacronismo de minha parte ter a expectativa de que Candido Jucá pudesse reconhecer a multiplicidade de organizações sociais nos mais diferentes, complexos e sofisticados grupos humanos e etnias. Mesmo assim, é interessante reparar que Candido Jucá Filho denuncia anacronismos no esforço de representação do passado, mas atribui às etnias indígenas e outros povos contemporâneos o rótulo de atrasados, na crença de que houvesse um percurso histórico linear no qual se insere todas as organizações sociais humanas: "Outra sorte de anacronismos se verifica quando atribuímos a povos contemporâneos, atrasados, contudo, de varias idades, sentimentos e juízos que caracterizam o homem civilizado. Apontarei um caso: o nativismo de Alencar. Pery o que é? Um cavalheiro dos mais polidos e requintados, com princípios de nobreza europeia, dentro da pele bronzeada de um bugre americano, habitando as florestas fluminenses. Um índio de carnaval...” (JUCÁ FILHO, 1929, p. 1).
} 
de suas identidades, possui sua cultura, a qual, muitas vezes, no contato com o outro, produz certo estranhamento e incompreensões das perspectivas singulares de cada um, gerando antagonismos. Para ele, de certo modo, seria natural que nos relatos de viajantes encontrássemos tais embates e recriminações em relação aos comportamentos observados e experimentados.

\section{Os periódicos e os debates de uma historicidade}

As diversas abordagens desses intelectuais demonstram ricas possibilidades no interior das temáticas do ensaio de Prado e das compreensões e representações particulares nos textos de seus críticos. A partir de suas noções e críticas, refutam ou endossam a tese da luxúria e cobiça como resultantes de uma tristeza generalizada. No conjunto das especificidades e divergências de cada um, é importante perceber que todos eles apontam para a necessidade de uma escrita da história (e mesmo da literatura ficcional) comprometida com pragmáticas voltadas para o seu presente. Ou melhor, advertem para a necessidade de uma reflexão histórica que tente provocar a ação, individual e conjunta, que norteie para um envolvimento éticopolítico, independente a quais definições de ética e política estão dispostas. Ao menos nos periódicos estudados neste texto, há certo clima desta necessidade de comprometimento com o estímulo à reflexão, à ação, sempre destacando que existem desafios colossais a serem enfrentados.

No interior da crítica à necessidade de representar o passado a partir de documentos, certos conceitos e métodos (possibilidade de distância histórica, atenção ao anacronismo, possibilidade de representação do passado, narrativa, características fragmentárias do passado, etc.) para a produção dessa pragmática, há também alguma expectativa de que se devam ou que possam ser utilizados recursos estéticos. É possível vislumbrar que a maioria entende que é possível (e mesmo necessário) utilizar elementos sensoriais e afetivos sem prejuízo da capacidade representativa, contanto que seja dada a devida atenção a certo rigor nos critérios para se investigar, interpretar e escrever sua narrativa.

Também parece haver a noção da importância da capacidade hermenêutica do intelectual, desde que não se excedam e que não sejam fundadas em arbitrariedades e não estejam centradas nas pessoalidades do autor. Entre esses intelectuais, há um nível interessante 
de variedades acerca das noções de que se pode representar objetivamente o passado, ou que as narrativas a respeito das experiências passadas, cada uma a seu jeito, podem contribuir para a compreensão da história. Do mesmo modo, parece haver uma percepção comum de que a história está sempre em reelaboração com o surgimento de novas compreensões teóricas, métodos e documentos.

É interessante apontar concepções de metanarrativas civilizacionais e do progresso. Há ainda outra complexidade importante, onde a ideia de progresso e civilização como um ideal a ser percorrido não se realiza necessariamente, a despeito dos homens. Nessa perspectiva, as pragmáticas parecem ser necessárias para que não se atrase ou para que se acelere o percurso. Já nas críticas de Humberto de Campos e Candido Jucá Filho, as concepções quanto ao ideal civilizacional ou do progresso parecem depender diretamente dos sujeitos para serem alcançadas, e podem, portanto, não se concretizar. No entanto, julgavam haver estágios ou graus de progresso civilizacional, onde acreditavam que sociedades étnicas (equivocadamente) não poderiam ser consideradas tão complexas e sofisticadas quanto seus modelos civilizacionais.

Mesmo assim, como no texto de Humberto de Campos, existe a possibilidade de crítica do modelo europeu e norte-americano como única possibilidade linear de civilização e progresso, atribuindo certa variedade à noção de civilização. Há aqui a perspectiva de que podem haver transcursos diversos, menos lineares, nos processos de formatação civilizacional.

Outra ideia notável é a noção de que uma determinada civilização, ou cultura, não necessariamente compreende e reconhece a outra em sua variedade, produzindo estranhamentos e antagonismos, como no texto de Campos. Ainda mais, encontram-se evidentes as tensões entre as concepções de que as sociedades e seus respectivos progressos civilizacionais são definidos por princípios étnicos e/ou culturais, e/ou socioeconômicos, e/ou geográficos.

É eminente como o saber a respeito do passado é de grande relevância para esses escritores na constituição de pragmáticas ético-políticas que instiguem à ação direcionada aos seus ideais civilizacionais e de progresso. As temáticas que compõem o Retrato do Brasil de Paulo Prado provocaram interessantes debates onde podemos observar compreensões acerca do passado de diversos intelectuais (das mais diversas ocupações). Do mesmo modo, é interessante fitar como poetas, romancistas e jornalistas tratam a temática da história e até produzem relevantes críticas à escrita da história a partir dos elementos da escrita que abordamos aqui 
como o da estética (o sensorial e afetivo) e o lógico-formal. Nesse sentido, as críticas apresentadas por esses letrados possibilitam uma interessante e importante variedade de perspectivas e comunhão de outras no interior da historicidade das décadas de vinte e trinta do século XX.

\section{Referências}

AGUIAR, Isabel Cristina Domingues. Prado e a semana de Arte Moderna: ensaios e correspondências. 2014. Tese (doutorado) - Faculdade de Ciências e Letras de Assis, Universidade Estadual Paulista, Assis, 2014. Disponível em: https://repositorio.unesp.br/handle/11449/115830. Acesso em: 23 jan. 2020.

ANDRADE, Mario de. O turista aprendiz. Diario Nacional: a democracia em marcha, São Paulo, p. 8, 26 mar. 1929. Disponível em: http://memoria.bn.br/DocReader/DocReader.aspx?bib=213829\&PagFis=4294\&Pesq=Retrato $\% 20 \mathrm{do} \% 20$ Brasil. Acesso em: 23 jan. 2020.

ANDRADE, Oswald de. Retoques ao "Retrato do Brasil": Oswald de Andrade critica Paulo Prado. O Jornal, Rio de Janeiro, domingo, p. 2, 6 jan. 1929. Disponível em: http://memoria.bn.br/DocReader/DocReader.aspx?bib=110523_02\&pesq=Retrato\%20do $\% 20$ Brasil\&pasta $=$ ano $\% 20192$. Acesso em: 22 jan. 2020.

CAMPOS, Humberto de. Vida Literária. Correio da Manhã, Rio de Janeiro, n. 10.411, p. 2, 3 dez. $1928 . \quad$ Disponível em: http://memoria.bn.br/DocReader/DocReader.aspx?bib=089842_03\&PagFis=36953\&Pesq=Re trato\%20do\%20Brasil. Acesso em: 22 jan. 2020.

GOMES, Ângela de Castro. A República, a história e o IHGB. Belo Horizonte: Fino Traço, 2009.

HABERMAS, Jürgen. Mudança estrutural da esfera pública: investigações quanto a uma categoria da sociedade burguesa. Rio de Janeiro: Tempo Brasileiro, 1984.

HARTOG. Regimes de historicidade: presentismo e experiências do tempo. Belo Horizonte: Autêntica, 2014.

HOLLANDA, Heloisa Buarque de; ARAÚJO, Lucia Nascimento. Ensaístas brasileiras: mulheres que escreveram sobre literatura e artes de 1860 a 1991. São Paulo: Rocco, 1993.

JUCÁ FILHO, Candido. Anachronismos. Correio da Manhã, Rio de Janeiro, $1^{a}$ edição, p. 1, 3 fev. $1929 . \quad$ Disponível em: 
http://memoria.bn.br/DocReader/DocReader.aspx?bib=089842_03\&pesq=Retrato $\% 20 \mathrm{do} \% 20$ Brasil\&pasta $=$ ano\%20192. Acesso em: 22 jan. 2020.

MUZART, Zahidé Lupinacci (org.). Escritoras brasileiras do século XIX. Florianópolis: Editora Mulheres, 2009.

PALTI, Elías. Opinión pública/Razón/Voluntad general. In: El tiempo de la política: El siglo XIX reconsiderado. Buenos Aires: Siglo XXI, 2007.

RIBEIRO, João. Chronica Literaria. Jornal do Brasil, $1^{a}$ edição, Rio de Janeiro, n. 309, p. 6, 26 dez. 1928. Disponível em: http://memoria.bn.br/DocReader/DocReader.aspx?bib=030015_04\&PagFis=71449\&Pesq=Pa ulo\%20Prado\%20Retrato\%20do\%20Brasil. Acesso em: 22 jan. 2020.

Submetido em: 29.10.2019.

Aprovado em: 26.05.2021. 